\title{
Primary alveolar soft part sarcoma of uterine corpus: a case report with immunohistochemical, ultrastructural study and review of literature
}

\author{
Giovanna Giordano ${ }^{1 *}$, Tiziana D’Adda ${ }^{1}$, Elena Varotti ${ }^{1}$, Giuseppe Crovini ${ }^{2}$ and Enrico Maria Silini ${ }^{1}$
}

\begin{abstract}
Background: Alveolar soft part sarcoma (ASPS) is a rare mesenchymal malignancy. ASPS usually occurs most commonly in the deep soft tissues of the thigh and buttock or the head and neck regions.

ASPS that originate from the uterine corpus are even more rare, with only 10 previous cases reported in the English literature.

Case presentation: In our case, the alveolar features were completely lost and the tumour shows a solid, nonalveolar pattern and the nuclei have marked variation in nuclear size, and multinucleation. The correct pathological diagnosis has been made by immuno- histochemical and ultrastructural features, which rvealed overexpression of TFE3 and peculiar cytoplasmic crystalline inclusions.

In this paper, an additional case of primary ASPS of uterine corpus is reported with immunohistochemical, ultrastructural study and review of literature in the effort to delineate its clinical and pathological features. In this unusual site, the diagnosis can be problematic because ASPS can mimic other primary or metastatic uterine neoplasms.

Conclusions: Thus, in this unusual presentation an essential diagnostic marker is the nuclear over-expression of TFE3 as well as ultrastructural study, which reveals the presence of peculiar cytoplasmic crystalline inclusions.
\end{abstract}

Keywords: Alveolar soft part sarcoma, Chromosomal translocation, TFE3 fusion protein

\section{Background}

Alveolar soft part sarcoma (ASPS) is a rare mesenchymal malignancy with distinctive histologic and ultrastructural appearance. ASPS was first described in 1952 by Christopherson et al. as a neoplasm with of uncertain histogenesis whose cells were arranged in a pattern mimicking the small air sacks (alveoli) of the lung [1].

In fact, this neoplasm usually shows uniform, organoid nests of polygonal cells, separated by fibrovascular septa and delicate capillary-sized vascular channels. A prominent cellular dyscohesion within the nests results in a distinctive pseudo-alveolar pattern. Sometimes, the alveolar features can be completely lost and the tumour may

\footnotetext{
* Correspondence: giovanna.giordano@unipr.it

'Department of Biomedical, Biotechnological and Translational Sciences, Pathological Anatomy and Histology Unit, Faculty of Medicine, University of Parma, Via Antonio Gramsci, 14, 43126 Parma, Italy

Full list of author information is available at the end of the article
}

show a solid, "non-alveolar" pattern [2]. Usually, the nuclei are round-to-polygonal and vesicular, with prominent nucleoli, but cells with marked variation in nuclear size, nuclear-cytoplasmatic inclusions, and multinucleation have been reported [3-5]. The cytoplasms are abundant granular and may contain periodic acid-Schiff-(PAS) positive, diastase (D)-resistant crystalline structures, rhomboid or rod-like in shape [6]. The first ultrastructural analysis of ASPS, made by Shipkey et al. in 1964 [6] and following studies confirmed the presence of distinctive cytoplasmic crystals which typically were intermingled with dense granules [7-9]. More recently, Ladanyi et al., by a combined ultrastructural and immunohistochemistry study, have demonstrated that these crystals consist of aggregates of the monocarboxylate transporter protein MCT1 and its cellular chaperone CD147 [10]. 
Recent cytogenetic studies revealed that ASPSs are characterized by specific chromosomal translocation $\operatorname{der}(17) t(X ; 17)$ (p11;q25) that fuses the transcription factor 3 (TFE3) gene at Xp11 to the ASPL gene at 17q25, producing an ASPL-TFE3 fusion protein [11]. This results in the aberrant and strong nuclear expression of TFE3 which is seen almost exclusively in tumours harbouring the TFE3 gene fusions, such as ASPSs and rare paediatric renal carcinomas [12].

ASPS usually affects adolescents and young adults in the second and third decades with slight female predominance [3]. In adults, this malignancy occurs most commonly in the deep soft tissues of the thigh or buttock, while in children and infants, the head and neck regions are often involved [3]. However, many reports have demonstrated that ASPS can be observed in unusual sites such as the mediastinum, stomach, breast, bone, and urinary bladder [13-19].

This neoplasm has been reported also in the female genital tract [20-26]. As far as we are aware, only 10 cases of ASPS of uterine corpus have been previously reported $[4,5,27-32]$. In these unusual sites, the diagnosis can be problematic because ASPS can mimic other primary or metastatic neoplasms.

In this paper, an additional case of primary ASPS of uterine corpus is reported with immunohistochemical, ultrastructural study and review of literature in the effort to delineate its clinical and pathological features.

\section{Case presentation}

A 66-year-old female was hospitalized for atypical vaginal bleeding and anaemia. On gynecologic examination, the uterus was enlarged and the cervix was prolapsed. Transvaginal ultrasound identified a well-circumscribed, intramural nodule measuring $5 \mathrm{~cm}$ in diameter, located in the uterine corpus. The patient underwent total abdominal hysterectomy and bilateral salpingo-oophorectomy. Intraoperatively, no ascites or adhesions were seen surrounding the uterus, ovaries, and salpinges. No enlarged pelvic lymph nodes were noted neither peritoneal lesions were found.

Gross pathologic examination revealed thickening of the cervical mucosa and an intramural, sharply circumscribed, round, firm, grey-white nodule with trabeculated cut surface located in the endocervix. The uterine corpus was enlarged and deformed because of an intramural nodule, measuring $5 \mathrm{~cm}$ in diameter. On cut section, this lesion was well circumscribed, soft, with irregular border, colour varying from yellow, brownish and grey and a large haemorrhagic zone centrally located (Fig. 1). The ovaries and salpinges were macroscopically unremarkable.

Histologically, the cervix showed atrophic epithelium and an intramural leiomyoma. The nodule of the uterine corpus was characterized by neoplastic cells arranged

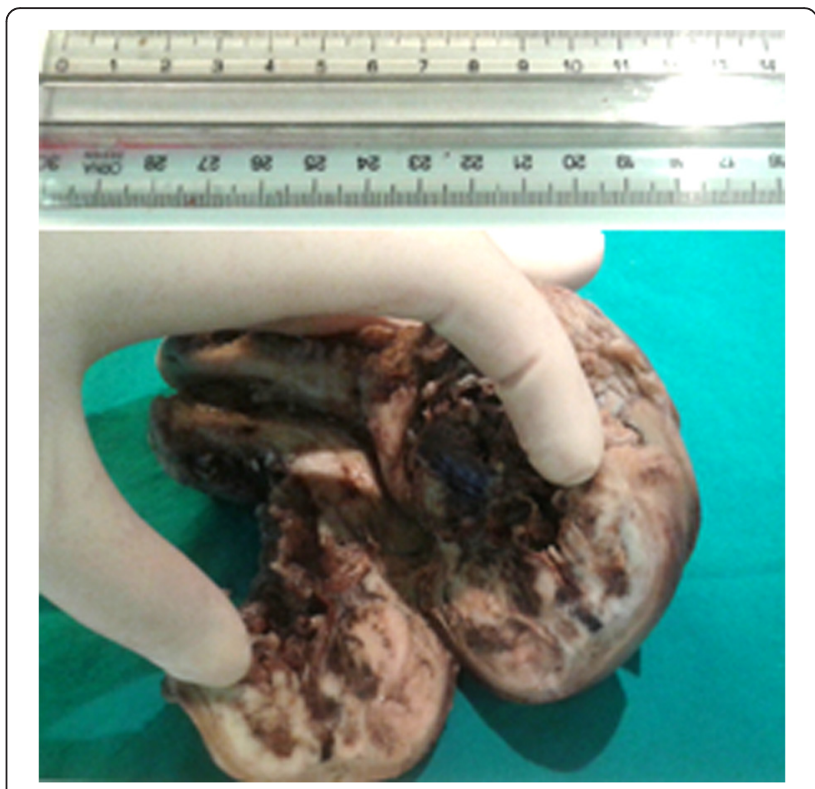

Fig. 1 On cut sections, the tumour was well circumscribed, soft, with irregular border and showed areas which varied from yellow, brownish and grey, with a central haemorrhagic area

in an organoid pattern (Fig. 2a), with nests surrounded by a delicate fibrovascular septa highlighted by PASD and anti-CD34 stains. Extensive degenerative changes, such as hyalinization, haemorrhage and hemosiderin deposits were observed (Fig. 2b). Most cells had abundant eosinophilic granular cytoplasm, distinct border and vesicular nuclei with prominent nucleolus (Fig. 2a). Other cells were large, with clear vacuolated cytoplasms (Fig. 2c). In some areas, the organoid pattern was lost and the tumour showed solid growth; in these areas, the cells were more spindled and showed nuclear pleomorphism, hyperchromasia and pseudo-inclusions and multinucleation (Fig. 2d). Necrosis and mitoses were absent.

On immunohistochemical analysis, the neoplasm showed focal immunoreactivity to muscle-specific actin, caldesmon and caldesmin. Ki 67 index was very low (Fig. 3a). Strong nuclear positivity to TFE3 was observed in all neoplastic cells (Fig. 3b). Immunostains for CD 34, CD10, microphthalmia transcription factor (MITF), myoglobin, S-100 protein, HMB-45, neuron-specific enolase, synaptophysin, chromogranin, cytokeratin, epithelial membrane antigen (EMA), cyclin D1 and alpha-inhibin were negative. Electron microscopy (EM) examination revealed cytoplasmic crystal inclusions showing periodic pattern of about $10 \mathrm{~nm}$ in channels resembling dilated sacs of endoplasmic reticulum (Fig. 4).

Because of immunohistochemical and ultrastructural features, such as focal immunoreactivity to musclespecific markers (actin, desmin, caldesmin), negativity to other makers, strong and diffuse nuclear positivity to TFE3 and the presence of cytoplasmic crystal inclusions, 


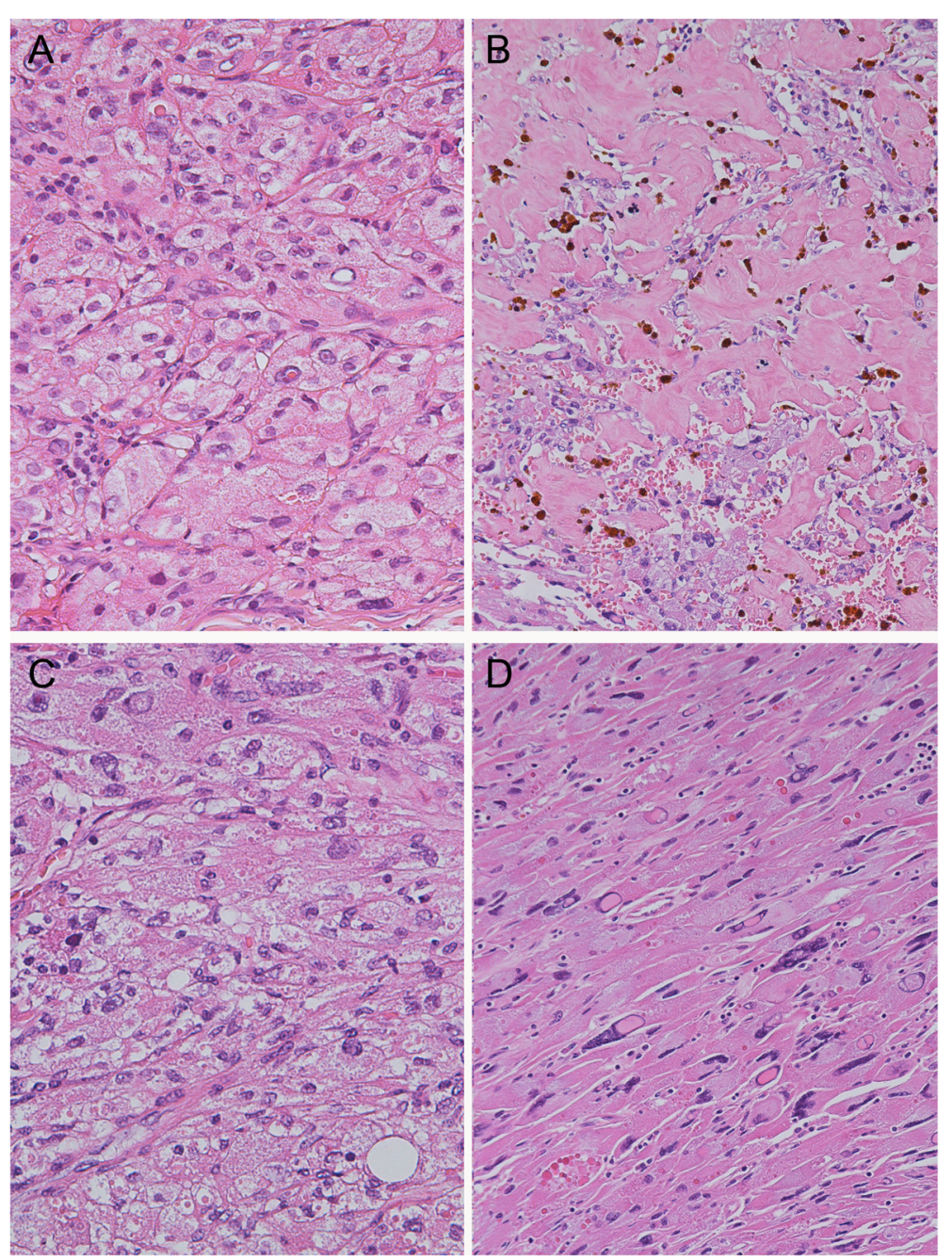

Fig. 2 Histologically, the tumour showed nests of neoplastic cells with abundant eosinophilic granular cytoplasm, distinct borders and vesicular nuclei with prominent nucleoli (a haematoxylin and eosin stain $\times 400$ ). Extensive degenerative changes, such as hyalinization with haemorrhagic and hemosiderin deposits, were observed (b haematoxylin and eosin stain $\times 200$ ). Other cells were large with clear vacuolated cytoplasms (c haematoxylin and eosin stain $\times 400$ ). In some areas, the organoid pattern was lost and the tumour showed solid growth, made spindle cells with nuclear, pleomorphism, hyperchromasia, pseudo-inclusions and multinucleations (d haematoxylin and eosin stain $\times 200$ )

the final pathologic diagnosis was primary uterine alveolar soft part sarcoma of uterine corpus. No images suggestive of other primary or metastatic lesions were observed on abdominal ultrasound, chest X-ray, total computed tomography or bone scan.

Seven months after surgery, the patient was free of disease. In fact, when she was readmitted for further examination, no abnormalities were found in both physical examination and imaging studies.

\section{Discussion}

ASPS is a rare malignant neoplasm, accounting for 0.5-1 \% of all soft part sarcomas [33]. ASPS that originate from the uterine corpus is even more rare, with only 10 previous cases reported in the English literature $[4,5,27-32]$. The main clinical and morphological features of 11 cases (including our present case) are summarized in Tables 1 and 2.

The age at diagnosis ranged from 14 to 66 years (median, 43 years). Abnormal uterine bleeding was present in all patients. The size of the neoplasm varied from 0.4 to $7 \mathrm{~cm}$ (median, $3 \mathrm{~cm}$ ) in diameter. In the majority of cases, the neoplasm was an intramural nodule. The diagnosis of ASPS in all cases was supported by histologic and EM examination, which revealed an alveolar pattern and the presence of cytoplasmic crystalline inclusions (Table 2).

Usually, the tumour nuclei were round-to-polygonal and vesicular, with prominent nucleoli, but cells with marked variation in nuclear size, nuclear cytoplasmatic inclusions and multinucleation, with very few mitoses have been observed in our case and in other ASPSs in the uterine corpus $[4,5]$ and extragenital sites $[3]$. 


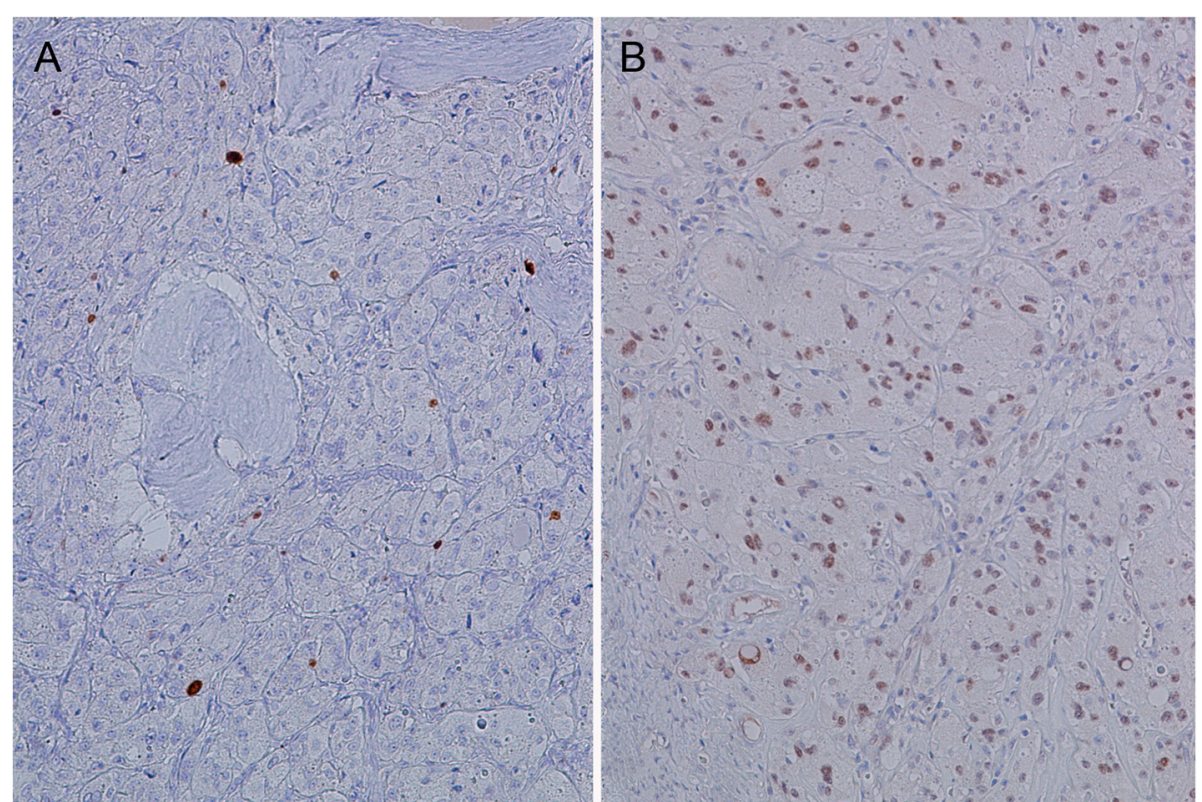

Fig. $3 \mathrm{Ki} 67$ index was very low $(\mathbf{a} \times 200)$. Strong nuclear positivity to TFE3 was observed in all cells $(\mathbf{b} \times 200)$

In our case, the alveolar features were completely lost and the tumour show a solid, non-alveolar pattern and the nuclei have marked variation in nuclear size, nuclear-cytoplasmatic inclusions and multinucleation. The correct pathological diagnosis has been made by immunohistochemical and ultrastructural features, which revealed focal immunoreactivity to muscle-specific markers (actin, desmin, caldesmon), negativity to other makers, strong and diffuse nuclear positivity to TFE3 and the presence of cytoplasmic crystal inclusions.

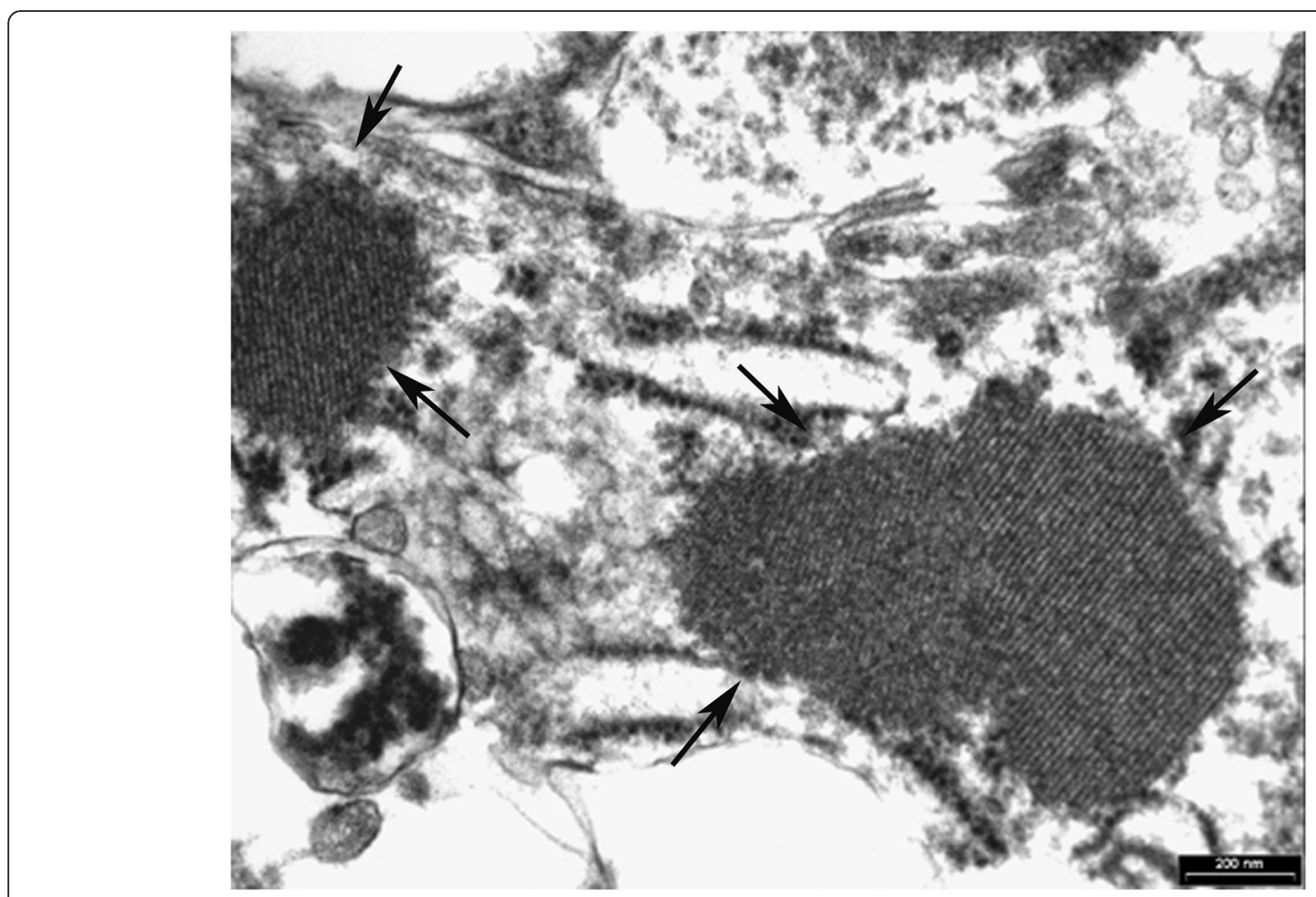

Fig. 4 In an ultrastructural study, neoplastic cells had cytoplasmic crystalline inclusions (arrows) showing unidirectional periodicity 
Table 1 R1: clinical features of ASPS of the uterus corpus

\begin{tabular}{|c|c|c|c|c|}
\hline Authors and years & Age & Clinical symptoms & Therapy & Follow-up \\
\hline Gray et al. (1986) [27] & 43 & Metromenorrhagia & Total hysterectomy & NED 9 Mo \\
\hline Nolan et al. (1990) [28] & 14 & Menorrhagia and expulsion of a necrotic mass per vagina & $\mathrm{HBSO}$ & NED $80 \mathrm{Mo}$ \\
\hline Guillou et al. (1991) [4] & 40 & Abdominal pelvic pain, intermenstrual bleeding & Total hysterectomy & NED $48 \mathrm{Mo}$ \\
\hline \multirow[t]{2}{*}{ Burch et al. (1994) [29] } & 47 & Intermenstrual bleeding & $\mathrm{HBSO}$ & NED12 Mo \\
\hline & 37 & Hypermenorrhea & Total hysterectomy & NED $66 \mathrm{Mo}$ \\
\hline Nielsen et al. (1995) [30] & 30 & Menometrorrhagia & Total hysterectomy & NED $66 \mathrm{Mo}$ \\
\hline \multirow[t]{2}{*}{ Radig et al. (1998) [31] } & 50 & Abnormal uterine bleeding & $\mathrm{HBSO}$ & NED $84 \mathrm{Mo}$ \\
\hline & 36 & Intermenstrual spotting, dysmenorrhoea & Hysterectomy & NED $8 \mathrm{Mo}$ \\
\hline Kasashima et al. (2007) [5] & 50 & Abnormal uterine bleeding & HBSO, lymph & NED $38 \mathrm{Mo}$ \\
\hline Zhang et al. (2012) [32] & 57 & Abnormal uterine bleeding & HBSO, lymph chem & NED $1 \mathrm{Mo}$ \\
\hline Present case & 66 & Abnormal uterine bleeding & HBSO & NED 7 Mo \\
\hline
\end{tabular}

ASPS alveolar soft part sarcoma, HBSO hysterectomy with bilateral salpingo-oophorectomy, NED not evidence of disease, Mo months

Moreover, the lesion was considered primary uterine alveolar soft part sarcoma because no images suggestive of other primary or metastatic lesions were observed on abdominal ultrasound, chest X-ray, total computed tomography or bone scan.

On the contrary, the review of literature revealed an immunohistochemical profile not very consistent with variable staining using other markers such as vimentin, desmin, myoglobin, muscle-specific actin, S-100 protein, HMB-45, neuron-specific enolase, synaptophysin, chromogranin, cytokeratin, EMA and NK1-C3 (melanomaspecific antibody) (Table 2). Thus, in our case, nuclear over-expression of TFE3 can be considered as an essential diagnostic marker for a correct pathological diagnosis. It has been demonstrated that aberrant and strong nuclear expression of TFE3 is seen exclusively in tumours which contain the TFE3 gene fusions [11], such as ASPS and rare paediatric renal carcinomas [12]. TFE3 immunoreactivity was first tested in the female genital tract in a case of ASPS located in the uterine cervix by Roma et al. in 2005 [26]. TFE3 immunoreactivity in cases of uterine corpus of ASPSs was evaluated only in our case and in the examples reported by Kasashima et al. and by Zhang L et al. [5, 32] (Table 2). The presence of crystalline inclusions on electron microscopy further supports the diagnosis of uterine ASPS.

ASPS of the uterine corpus enters in the differential diagnosis with other neoplasms presenting an admixture of spindle-to-epithelioid cells with eosinophilic-to-clear cytoplasm such as epithelioid smooth muscle tumours, epithelioid endometrial stromal tumours, perivascular epithelioid cell tumours (PECOMAs), uterine rhabdoid tumours, carcinomas, melanoma and malignant paraganglioma. These tumours characteristically do not show expression of TFE3 on immunohistochemical analysis and have other peculiar morphologic and immunohistochemical features.
Epithelioid smooth muscle tumours are composed by mixtures of epithelioid, clear cell. A transition to typical smooth muscle cells in most instances confirms the smooth muscle nature of these tumours [34] and are diffuse immunoreactive for actin and desmin.

Endometrial stromal tumours with a prominent component of epithelioid cells and abundant eosinophilic cytoplasm usually show areas with fusiform cells, characteristic arterioles and strong diffuse cytoplasmic immunoreactivity for vimentin and for CD10 [35].

PECOMAs can arise in the uterus and are characterized by varying amounts of spindle and epithelioid cells with clear to eosinophilic cytoplasm, with immunoreactivity for melanocytic markers, most frequently HMB-45 [36].

Malignant rhabdoid tumour is a highly aggressive tumour in adults and rapidly fatal and was first reported to have been found in the uterus in 1989 [37]. Histologically, this rare neoplasm shows solid sheets of large cells with deep eosinophilic cytoplasm, eosinophilic hyaline cytoplasmic inclusions, eccentric vesicular nuclei and prominent nucleoli. On immunohistochemical analysis, neoplastic cells reveal cytoplasmic staining for vimentin [38] and keratins [38, 39].

Melanoma and carcinoma can be differentiated from ASPS because of greater cytologic atypia, pleomorphism, higher mitotic activity and immunoreactivity, respectively, for epithelial makers and for melanoma-specific antibodies.

Malignant paraganglioma is characterized by polygonal to oval cells arranged in distinctive cell balls, called Zellballen, and shows more pronounced cell pleomorphism and immunoreactivity for neuroendocrine markers, such as neuron-specific enolase, protein gene product 9.5 , synaptophysin and the presence of neurosecretory granules on EM examination [40].

In extragenital sites, ASPS presents an indolent clinical course with unpredictable prognosis. Metastases to the 
Table 2 Pathological findings of ASPS of the uterus corpus

\begin{tabular}{|c|c|c|c|c|}
\hline $\begin{array}{l}\text { Authors } \\
\text { and years }\end{array}$ & Macroscopic findings & Microscopic findings & Immunohistochemical findings & Electron microscopy \\
\hline $\begin{array}{l}\text { Gray et al. } \\
\text { (1986) [27] }\end{array}$ & $\begin{array}{l}\text { Uncapsulated, circumscribed intramyometrial } \\
\text { nodule, } 0.4 \mathrm{~cm}\end{array}$ & $\begin{array}{l}\text { Large cell, arranged in organoid appearance separated by } \\
\text { delicate fibrovascular stroma }\end{array}$ & ND & $\begin{array}{l}\text { Membrane bound crystalline } \\
\text { granule inclusions in the } \\
\text { cytoplasm }\end{array}$ \\
\hline $\begin{array}{l}\text { Nolan and } \\
\text { Gaffney (1990) } \\
\text { [28] }\end{array}$ & $\begin{array}{l}\text { Mass of } 7 \mathrm{~cm} \text {, bulging into endometrial } \\
\text { cavity }\end{array}$ & $\begin{array}{l}\text { Large cells with granular and vacuolated cytoplasms, organoid } \\
\text { arrangement, separated by fibrovascular septae.PASDR crystals }\end{array}$ & ND & $\begin{array}{l}\text { Intracytoplasmic crystalline } \\
\text { inclusions }\end{array}$ \\
\hline $\begin{array}{l}\text { Guillou et al. } \\
\text { (1991) [4] }\end{array}$ & $\begin{array}{l}3 \times 2.5 \times 2.5 \mathrm{~cm} \text { well-circumscribed } \\
\text { intramyometrial nodule }\end{array}$ & $\begin{array}{l}\text { Uncapsulated lesion pushing border delineated by } \\
\text { endometrium, large cells with organoid arrangement, separated } \\
\text { by fibrovascular septae, granular cytoplasms with crystals. } \\
\text { Areas with nuclear pleomorphism }\end{array}$ & $\begin{array}{l}\text { POS Vim, focal POS HMB45, NKI/C3, } \\
\text { patchy dot-like cytokeratin Iw POS }\end{array}$ & ND \\
\hline $\begin{array}{l}\text { Burch et al. } \\
\text { (1994) [29] }\end{array}$ & 3-cm endometrial polyp & Large cells with granular cytoplasm, crystals on PAS D & ND & $\begin{array}{l}\text { Intracytoplasmic crystalline } \\
\text { inclusions }\end{array}$ \\
\hline \multirow[t]{2}{*}{$\begin{array}{l}\text { Nielsen et al. } \\
\text { (1995) [30] }\end{array}$} & $1-\mathrm{cm}$ intramural nodule & $\begin{array}{l}\text { Large cell, arranged in organoid appearance separated by } \\
\text { delicate fibrovascular stroma crystals on PAS D }\end{array}$ & ND & ND \\
\hline & 3.5-cm submucosal nodule & $\begin{array}{l}\text { Large cell, arranged in organoid appearance separated by } \\
\text { delicate fibrovascular stroma, crystals on PAS D }\end{array}$ & ND & ND \\
\hline \multirow[t]{2}{*}{$\begin{array}{l}\text { Radig K et al. } \\
\text { (1998) [31] }\end{array}$} & $\begin{array}{l}\text { 3-cm well-circumscribed yellow-whitish, } \\
\text { intramural nodule }\end{array}$ & $\begin{array}{l}\text { Pseudoalveolar and trabecular pattern, polygonal and round } \\
\text { cells vesicular nuclei, with nucleoli, crystals on PAS D }\end{array}$ & NEG for S100, Ck, EMA, POS caldes & $\begin{array}{l}\text { Intracytoplasmic crystalline } \\
\text { inclusions }\end{array}$ \\
\hline & 4.5-cm well-circumscribed, intramural nodule & Pseudoalveolar pattern, granular & ND & $\begin{array}{l}\text { Intracytoplasmic crystalline } \\
\text { inclusions absent }\end{array}$ \\
\hline \multirow[t]{2}{*}{$\begin{array}{l}\text { Kasashima S } \\
\text { et al. (2007) [5] }\end{array}$} & \multirow[t]{2}{*}{$\begin{array}{l}1.9 \times 1.9 \times 1.0 \mathrm{~cm} \text { greyish, endometrial } \\
\text { exophytic nodule }\end{array}$} & $\begin{array}{l}\text { Large cells with organoid arrangement, separated by } \\
\text { fibrovascular septae, granular cytoplasms with crystals }\end{array}$ & Nuclear POS: TFE3, PGR, ER, CD10 & \multirow[t]{2}{*}{ ND } \\
\hline & & $\begin{array}{l}\text { Vesicular nuclei and pleomorphic nuclei and multinucleated } \\
\text { cells. Mitoses very rare. No M Lym }\end{array}$ & $\begin{array}{l}\text { NEG: Vim, caldes, Sma, Myo, HMB45, S100, } \\
\text { EMA, Chrom, Syn, Myoge, Myogl }\end{array}$ & \\
\hline \multirow[t]{2}{*}{$\begin{array}{l}\text { Zhang et al. } \\
\text { (2012) [32] }\end{array}$} & \multirow{2}{*}{$\begin{array}{l}2.4 \times 2.0 \times 1.8 \mathrm{~cm} \text { yellow-whitish exophytic } \\
\text { tumour, sub-endometrium of the lower } \\
\text { uterine segment }\end{array}$} & \multirow[t]{2}{*}{$\begin{array}{l}\text { Large cells with organoid arrangement, separated by delicate } \\
\text { fibrovascular septae, granular cytoplasms with crystalsM lymph }\end{array}$} & $\begin{array}{l}\text { NEG: Ae1/AE3, EMA, Sma, Des, S-100, } \\
\text { CD10, Synapt, Chrom }\end{array}$ & \multirow[t]{2}{*}{ ND } \\
\hline & & & Ki67: 5 \% diffuse POS Nuclear TFE3 & \\
\hline \multirow[t]{2}{*}{ Present case } & \multirow[t]{2}{*}{$\begin{array}{l}\text { 5-cm intramural nodule, well-circumscribed, } \\
\text { with irregular border, soft yellow, brownish } \\
\text { and grey, with a large haemorrhagic zone } \\
\text { centrally located }\end{array}$} & $\begin{array}{l}\text { Solid "non-organoid" pattern, abundant eosinophilic granular } \\
\text { cytoplasm, with distinct border, and vesicular nuclei and } \\
\text { prominent nucleolus }\end{array}$ & $\begin{array}{l}\text { Focal POS to Sma, desm, Caldes and } \\
\text { diffuse and strong nuclear POS to TFE3 } \\
\text { NEG: Ae1/AE3, EMA, Sma, Des, S-100, } \\
\text { CD10, NSE, Synapt, Chrom, inh, MiTF }\end{array}$ & \multirow[t]{2}{*}{$\begin{array}{l}\text { Intracytoplasmic crystalline } \\
\text { inclusions }\end{array}$} \\
\hline & & $\begin{array}{l}\text { Areas with spindle elements with nuclear, pleomorphism, } \\
\text { hyperchromasia, nuclear cytoplasmic pseudo-inclusions } \\
\text { and multinucleations }\end{array}$ & Diffuse POS nuclear TFE3 & \\
\hline
\end{tabular}

ASPS alveolar soft part sarcoma, Caldes caldesmin, Chrom chromogranin, CK cytokeratin, EMA epithelial membrane antigen, ER oestrogen receptor, caldes caldesmon, Immu immunohistochemistry, inh alpha-inhibin, Lym lymph node, Iw low weight, MLymph lymphonodal metastasis, MITF microphthalmia transcription factor, Mo months, Myoge myogenin, Myogl myoglobin, ND not done, NSE neuron-specific enolase, PASDR periodic acid-Schiff diastase resistant, $P G R$ progesterone receptor, POS positivity, Sma muscle-specific actin, Synapt synaptophysin, TFE3 transcription factor 3, Vim vimentin 
lungs, bone and brain are the main cause of death [41, 42]. Lesions with size less than $5 \mathrm{~cm}$ in diameter seem to be correlated with a more favourable outcome [43]. ASPS in the uterine corpus has a better prognosis than ASPSs in the soft tissues and other cases located in the vagina. All patients with ASPS located in the uterine corpus were alive and well at the time of the last follow-up (Table 1). In contrast, one of six patients with vaginal ASPS died as a result of the tumour. Initially, this patient had a recurrence 4 months after local excision and external radiation therapy and then died of the disease with pulmonary metastases 25 months later $[23,24]$. Another patient with vaginal ASPS had a recurrent $1.5-\mathrm{cm}$ mass, 4 months after the initial diagnosis [25].

The more favourable prognosis in ASPS located in the uterine corpus may be due to small tumour size, anatomical location or relative short duration of follow-up. Indeed, in all patients, the ASPS of the uterine corpus, except for the present case and the case reported by Nolan and Gaffney, measured less than $5 \mathrm{~cm}$ [28] (Table 2). Only in the case reported by Zhang et al. was the pelvic and para-aortic lymph node metastasis observed at diagnosis, but the duration of follow-up in this case was short (9 months) and it is not possible to establish its outcome [32].

\section{Conclusions}

An essential diagnostic marker in this unusual presentation of neoplasm is the nuclear over-expression of TFE3 as well as ultrastructural study, which reveals the presence of peculiar cytoplasmic crystalline inclusions.

Moreover, in our opinion, a larger number of cases of ASPS in the female genital tract with longer follow-up and pathological findings including sizes should help to better define the biological nature of ASPS in the uterine corpus. In addition, although lymph nodes metastasis was observed only in the case of Zhang et al., surgical staging with complete pelvic lymph nodes sampling could be useful to evaluate therapy and prognosis of this rare neoplasm.

\section{Consent}

Written informed consent was obtained from the patient for publication of this case report and any accompanying images.

\footnotetext{
Abbreviations

ASPS: alveolar soft part sarcoma; Caldes: caldesmon; Chrom: chromogranin; CK: cytokeratin; EM: electron microscopy; EMA: epithelial membrane antigen; ER: oestrogen receptor; Desm: desmin; HBSO: hysterectomy with bilateral salpingo-oophorectomy; Immu: immunohistochemistry; inh: alpha-inhibin; Lym: lymph node; Iw: low weight; MLymph: lymphonodal metastasis; MITF: microphthalmia transcription factor; Mo: months; Myoge: myogenin; Myogl: myoglobin; NED: not evidence of disease; ND: not done; NSE: neuronspecific enolase; PASDR: periodic acid-Schiff diastase resistant; PGR: progesterone receptor; POS: positivity; Sma: muscle-specific actin; Synapt: synaptophysin; TFE3: transcription factor 3; Vim: vimentin.
}

\section{Competing interests}

The authors declare that they have no competing interests.

\section{Authors' contributions}

GG and ES carried out the study design and writing. TD did the electron microscopy study. EV participated in the literature search. GC performed the operation of the patient. All authors read and approved the final manuscript.

\section{Acknowledgements}

The authors wish to thank Mrs Emilia Corradini and Mrs Gabriella Becchi for the technical assistance.

\section{Author details}

'Department of Biomedical, Biotechnological and Translational Sciences, Pathological Anatomy and Histology Unit, Faculty of Medicine, University of Parma, Via Antonio Gramsci, 14, 43126 Parma, Italy. ${ }^{2}$ Department of Gynaecology and Obstetrics, Hospital of Fidenza, Parma, Italy.

Received: 15 October 2015 Accepted: 26 January 2016

Published online: 02 February 2016

\section{References}

1. Christopherson WM, Foote FW, Stewart FW. Alveolar soft part sarcomas: structurally characteristic tumors of uncertain histogenesis. Cancer. 1952:5:100-11.

2. Fanburg-Smith JC, Miettinen M, Folpe AL, Weiss SW, Childers EL. Lingual alveolar soft part sarcoma; 14 cases: novel clinical and morphological observations. Histopathology. 2004;45:526-37. doi:10.1111/j.1365-2559.2004. 01966.X.

3. Folpe AL, Deyrup AT. Alveolar soft-part sarcoma: a review and update. J Clin Pathol. 2006;59:1127-32. doi:10.1136/jcp.2005.031120.

4. Guillou L, Lamoureux E, Masse S, Costa J. Alveolar soft-part sarcoma of the uterine corpus: histological, immunocytochemical and ultrastructural study of a case. Virchows Arch A Pathol Anat Histopathol. 1991:418:467-71.

5. Kasashima S, Minato H, Kobayashi M, Ueda Y, Oda Y, Hashimoto S, et al. Alveolar soft part sarcoma of the endometrium with expression of CD10 and hormone receptors. APMIS.2007;115:861-5. doi:10.1111/j.1600-0463.2007. apm_635.x.

6. Shipkey FH, Lieberman PH, Foote Jr FW, Stewart FW. Ultrastructure of alveolar soft part sarcoma. Cancer. 1964;17:821-30.

7. Font RL, Jurco S, Zimmerman LE. Alveolar soft-part sarcoma of the orbit: a clinicopathologic analysis of seventeen cases and a review of the literature. Hum Pathol. 1982:13:569-79.

8. DeSchryver-Kecskemeti K, Kraus FT, Engleman W, Lacy PE. Alveolar soft-part sarcoma — a malignant angioreninoma: histochemical, immunocytochemical, and electron-microscopic study of four cases. Am J Surg Pathol. 1982;6:5-18.

9. Mukai M, Iri H, Nakajima T, Hirose S, Torikata C, Kageyama K, et al. Alveolar soft-part sarcoma. A review on its histogenesis and further studies based on electron microscopy, immunohistochemistry, and biochemistry. Am J Surg Pathol. 1983;7:679-89.

10. Ladanyi M, Antonescu CR, Drobnjak M, Baren A, Lui MY, Golde DW, et al. The precrystalline cytoplasmic granules of alveolar soft part sarcoma contain monocarboxylate transporter 1 and CD147. Am J Pathol. 2002;160:1215-21. doi: 10.1016/S0002-9440(10)62548-5.

11. Ladanyi M, Lui MY, Antonescu CR, Krause-Boehm A, Meindl A, Argani P, et al. The $\operatorname{der}(17) t(X ; 17)(p 11 ; q 25)$ of human alveolar soft part sarcoma fuses the TFE3 transcription factor gene to ASPL, a novel gene at 17q25. Oncogene. 2001;20: 48-57. doi:10.1038/sj.onc.1204074.

12. Argani $P$, Lal $P$, Hutchinson $B$, Lui MY, Reuter VE, Ladanyi M. Aberrant nuclear immunoreactivity for TFE3 in neoplasms with TFE3 gene fusions: a sensitive and specific immunohistochemical assay. Am J Surg Pathol. 2003; 27:750-61.

13. Flieder DB, Moran CA, Suster S. Primary alveolar soft-part sarcoma of the mediastinum: a clinicopathological and immunohistochemical study of two cases. Histopathology. 1997;31:469-73.

14. Yagihashi S, Yagihashi N, Hase Y, Nagai K, Alguacil-Garcia A. A primary alveolar soft-part sarcoma of stomach. Am J Surg Pathol. 1991;15:399-406.

15. Wu J, Brinker DA, Haas M, Montgomery EA, Argani P. Primary alveolar soft part sarcoma (ASPS) of the breast. Int J Surg Pathol. 2005;13:81-5. 
16. Liu TT, Chou YH, Lai CR, Chen CM, Tsou MH, Lin HH, et al. Breast mass due to alveolar soft part sarcoma of the pectoris major muscle. Eur J Radiol. 1997;24:57-9. doi:10.1016/S0720-048X(96)01117-5.

17. Aisner SC, Beebe K, Blacksin M, Mirani N, Hameed M. Primary alveolar soft part sarcoma of fibula demonstrating ASPLTFE3 fusion: a case report and review of the literature. Skeletal Radiol. 2008;37:1047-51. doi:10.1007/ s00256-008-0540-6.

18. Park YK, Unni KK, Kim YW, Han CS, Yang MH, Wenger DE, et al. Primary alveolar soft part sarcoma of bone. Histopathology. 1999;35:411-17. doi:10. 1046/j.1365-2559.1999.035005411.x.

19. Amin MB, Patel RM, Oliveira P, Cabrera R, Carneiro V, Preto M, et al. Alveolar soft-part sarcoma of the urinary bladder with urethral recurrence: a unique case with emphasis on differential diagnoses and diagnostic utility of an immunohistochemical panel including TFE3. Am J Surg Pathol. 2006;30: 1322-25. doi:10.1097/01.pas.0000213298.34520.2b.

20. Tobon H, Amortegui AJ, Murphy Al. Alveolar soft part sarcoma of the vagina. Pa Med. 1976;79:55-7.

21. Kasai K, Yoshida Y, Okumura M. Alveolar soft part sarcoma in the vagina: clinical features and morphology. Gynecol Oncol. 1980;9:227-36.

22. Flint A, Gikas PW, Roberts JA. Alveolar soft part sarcoma of the uterine cervix. Gynecol Oncol. 1985;22:263-67.

23. Chapman GW, Benda J, Williams T. Alveolar soft-part sarcoma of the vagina. Gynecol Oncol. 1984;18:125-29.

24. Zaleski S, Setum C, Benda J. Cytologic presentation of alveolar soft-part sarcoma of the vagina. A case report. Acta Cytol. 1986;30:665-70.

25. Chang HC, Hsueh S, Ho YS, Chang MY, Soong YK. Alveolar soft part sarcoma of the vagina. A case report. J Reprod Med. 1994;39:121-5.

26. Roma AA, Yang B, Senior ME, Goldblum J. TFE3 immunoreactivity in alveolar soft part sarcoma of the uterine cervix: case report. Int J Gynecol Pathol. 2005;24:131-35. doi:10.1097/01.PGP.0000148343.07759.E1.

27. Gray Jr GF, Glick AD, Kurtin PJ, Jones 3rd HW. Alveolar soft part sarcoma of the uterus. Hum Pathol. 1986;17:297-300.

28. Nolan NP, Gaffney EF. Alveolar soft part sarcoma of the uterus. Histopathology. 1990;16:97-9.

29. Burch DJ, Hitchcock A, Masson GM. Alveolar soft part sarcoma of the uterus: case report and review of the literature. Gynecol Oncol. 1994;54:91-4.

30. Nielsen GP, Oliva E, Young RH, Rosenberg AE, Dickersin GR, Scully RE. Alveolar soft-part sarcoma of the female genital tract: a report of nine cases and review of the literature. Int J Gynecol Pathol. 1995;14:283-92.

31. Radig K, Buhtz P, Roessner A. Alveolar soft part sarcoma of the uterine corpus. Report of two cases and review of the literature. Pathol Res Pract. 1998;194:59-63. doi:10.1016/S0344-0338(98)80013-7.

32. Zhang LL, Tang Q, Wang Z, Zhang XS. Alveolar soft part sarcoma of the uterine corpus with pelvic lymph node metastasis: case report and literature review. Int J Clin Exp Pathol. 2012;5:715-9.

33. Weiss SW, Goldblum JR. Malignant tumors of uncertain type. In Enzinger and Weiss's soft tissue tumors, 4th edn. Mosby- Harcourt, Philadelphia, 2001; 1509-21

34. Kurman RJ, Norris HJ. Mesenchymal tumors of the uterus. VI. Epithelioid smooth muscle tumors including leiomyoblastoma and clear-cell leiomyoma: a clinical and pathologic analysis of 26 cases. Cancer. 1976:37:1853-65.

35. Oliva E, Clement PB, Young RH. Epithelioid endometrial and endometrioid stromal tumors: a report of four cases emphasizing their distinction from epithelioid smooth muscle tumors and other oxyphilic uterine and extrauterine tumors. Int J Gynecol Pathol. 2002;21:48-55.

36. Fadare O. Perivascular epithelioid cell tumor (PEComa) of the uterus: an outcome-based clinicopathologic analysis of 41 reported cases. Adv Anat Pathol. 2008;15:63-75. doi:10.1097/PAP.0b013e31816613b0.

37. Cho KR, Rosenshein NB, Epstein Jl. Malignant rhabdoid tumor of the uterus. Int J Gynecol Pathol. 1989;8:381-7.

38. Cattani MG, Viale G, Santini D, Martinelli GN. Malignant rhabdoid tumour of the uterus: an immunohistochemical and ultrastructural study. Virchows Arch A Pathol Anat Histopathol. 1992;420:459-62.

39. Fanburg-Smith JC, Hengge M, Hengge UR, Smith Jr JS, Miettinen M. Extrarenal rhabdoid tumors of soft tissue: a clinicopathologic and immunohistochemical study of 18 cases. Ann Diagn Pathol. 1998;2:351-62. doi:10.1016/S1092-9134(98)80038-5.

40. Beham A, Schmid C, Fletcher CD, Auböck L, Pickel H. Malignant paraganglioma of the uterus. Virchows Arch A Pathol Anat Histopathol. 1992;420:453-7.
41. Lieberman PH, Brennan MF, Kimmel M, Erlandson RA, Garin-Chesa P, Flehinger BY. Alveolar soft-part sarcoma. A clinico-pathologic study of half a century. Cancer. 1989;63:1-13.

42. Portera Jr CA, Ho V, Patel SR, Hunt KK, Feig BW, Respondek PM, et al. Alveolar soft part sarcoma: clinical course and patterns of metastasis in 70 patients treated at a single institution. Cancer. 2001;91:585-91. doi:10.1002/ 1097-0142(20010201)91:3<585::AID-CNCR1038>3.0.CO;2-0.

43. Evans HL. Alveolar soft-part sarcoma. A study of 13 typical examples and one with a histologically atypical component. Cancer. 1985;55:912-7.

\section{Submit your next manuscript to BioMed Central and we will help you at every step:}

- We accept pre-submission inquiries

- Our selector tool helps you to find the most relevant journal

- We provide round the clock customer support

- Convenient online submission

- Thorough peer review

- Inclusion in PubMed and all major indexing services

- Maximum visibility for your research

Submit your manuscript at www.biomedcentral.com/submit
Biomed Central 